\title{
UM MODO DE TRADUZIR FIGURAS DO PASSADO: CADERNOS DE UM PROFESSOR CATARINENSE
}

CUNHA, M. T. S.; SOUZA, F. de. F. Viver e escrever. Cadernos e escritas ordinárias de um professor catarinense (séc. XX). Florianópolis: Insular, 2015.

Resenhado por: José Edimar de Souza ${ }^{1}$

A história, como operação intelectual interpretativa, organiza, compõe, constrói e critica as fontes à luz de uma teoria. A operação histórica é resultado de uma combinação de um lugar social, de práticas científicas e de uma escrita. Para Oliveira e Souza (2016), a história é mediatizada pelas técnicas, pelas lentes curiosas do investigador no processo de transformação entre o documento e sua construção. A obra de Maria Teresa Santos Cunha e de Flávia de Freitas Souza apresenta um modo de traduzir o passado, um passado edificado pelas lembranças de práticas de um determinado espaço e tempo, de sujeitos que procuraram em seu tempo vivido, capturar pelas suas mais distintas idiossincrasias as suas interpretações sobre o cotidiano vivido.

Para Souza e Fischer (2012), as mudanças recorrentes e cotidianas nas práticas sociais têm contribuído para a rápida produção do esquecimento. Além disso, a cada geração, a cada renovação, partes inteiras da herança cultural da humanidade desaparecem da memória ao mesmo tempo em que outros elementos da cultura são contemplados. Nesse sentido, o conhecimento do passado de uma instituição, de uma comunidade, de uma família ou dos membros de um grupo social permite reconhecer e refletir sobre as mudanças e os processos ocorridos ao longo do tempo.

A história da sociedade é, entre outras coisas, a história de pessoas que vivem unidas, definíveis em termos sociológicos. A história é história do modo real como os homens reais produzem suas condições reais de existência. Somos aquilo de que nos recordamos; aquilo que não esquecemos; o que conseguimos lembrar. Narrar uma vida, contar uma história, suportar as memórias que compõem a complexa relação dos sujeitos e do modo como tecem suas trajetórias aos diferentes contextos de atuação é um dos desafios propostos pelas autoras da obra Viver e escrever. Cadernos e escritas ordinárias de um professor catarinense (Séc. XX).

Maria Teresa Santos Cunha é doutora em Educação/História e Filosofia pela Universidade de São Paulo. Professora Associada VII do Departamento de História da Universidade do Estado de Santa Catarina (UDESC) e docente dos Programas de PósGraduação em Educação e Pós-graduação em História da (UDESC). Bolsista Produtividade 
em Pesquisa/CNPq/ Nível 2. Flávia de Freitas Souza é graduada em História pela Universidade do Estado de Santa Catarina (UDESC). E atuou como bolsista na modalidade PIBIC/CNPq do grupo de pesquisa: Ensino de História, Memória e Culturas, no projeto de pesquisa: "Perfil de uma biblioteca de professores catarinenses - Victor Márcia Konder (1920-2005) e Elpídio Barbosa (1909-1967)”, coordenado pela professora Maria Teresa Santos Cunha.

A obra está organizada em duas partes. Inicia com apresentação da obra assinada pela professora Maria Teresa. Na sequência, as seções são: Victor Márcio Konder: a memória valorizada - Cadernos de um professor catarinense (século XX) e Escritas avulsas, escritas para a história: o acervo de cadernos do professor Victor Márcio Konder (1920-2005). Além disso, ao final de cada seção existem as referências bibliográficas e ainda uma relação de imagens sobre o acervo de livros do professor Kondor.

Ao apresentar a obra Maria Teresa enfatiza o objetivo da obra, que consiste em analisar um acervo pessoal de cadernos com informações. Trata-se do acervo pessoal do professor catarinense Victor Márcio Konder. O acervo reporta ao recorte temporal das décadas de 1960 a 1980 e consiste em quarenta e cinco cadernos manuscritos onde foi possível mapear aspectos da vida do proprietário. Além disso, a análise destaca a partir das escritas cotidianas, das testemunhas de uma construção escrita de si, a figura de um intelectual, homem de letras de seu tempo.

As formas de arquivamento de memórias suscitam modos singulares de compor uma representação sobre si, sobre um lugar ou sobre alguma coisa. Artières (1998) argumenta que se arquivam aspectos da vida cotidiana como forma de examinar e refletir sobre aquilo que lhes acontece, sobre as práticas e experiências. Esses registros podem ser reveladores, pois representam o modo como os sujeitos se projetam e/ou gostariam que fossem identificados pelas suas ações, suas escolhas, sua singularidade.

O acervo ainda compõe como objeto e patrimônio da cultura material da escola. Nesse sentido, a contribuição para os estudos de identificação e compreensão das culturas escolares endossa a relevância da obra, dos registros e das análises estabelecidas pelas autoras. Para Escolano Benito (2015, p. 56) é na escola que a cultura tem alcançado maior impacto na modernidade, pois, "[...] querida u odiada, pero siempre recordada, ella fue um escenario clave de nuestra sociabilidad [...] em el desenvolvimiento de nuestra propia identidade narrativa y um ámbito de creación de cultura [...]”.

A cultura como enunciação se concentra na significação e institucionalização, é pela relação cultural com o passado que as possibilidades e sentidos emergem pela atividade historiográfica, pelas articulações e pelos processos que a experiência objetiva transformar os sujeitos em sua relação com a história.

A primeira parte da obra, intitulada Victor Márcio Konder: a memória valorizada - Cadernos de um professor catarinense (século XX) as autoras dedicam demorados 
argumentos sobre as relações do biografado e os cenários políticos, social e cultural de sua trajetória de vida e profissional. Observa-se que a influência política envolve as escolhas e as decisões que Victor Márcio Konder realiza no curso de sua vida de diferentes maneiras: filiado ao Partido Comunista Brasileiro; como jornalista e diretor do Jornal de Santa Catarina ou ainda como professor de História, Antropologia e Cultura Brasileira e Economia, na Faculdade de Educação da Universidade do Estado de Santa Catarina.

Esta seção ainda destaca a relevância das escritas ordinárias, anotações, desenhos, pensamentos que se atravessam em diferentes fases da vida de Victor Márcio Konder: durante audição de uma aula, como estudante ou no momento em que realizava o planejamento de suas aulas, quando já era professor. Segundo Mignot (2003), estes registros figuram como pistas, vestígios para compreender as memórias de uma família, de uma instituição, de uma época.

Na segunda parte da obra, intitulada Escritas avulsas, escritas para a história: o acervo de Cadernos do professor Victor Márcio Konder (1920-2005) as autoras destacam as potencialidades de pesquisa a partir dos acervos pessoais. Nesse sentido, reforçam o argumento de que tais acervos revelam questões profundas e sensíveis a respeito daqueles que os produziram. Vidal $(2007$, p. 6) a este respeito acrescenta que "[...] sua leitura nos permite ter um acesso privilegiado à sensibilidade de um período, para entender de forma mais aguda com o se articula uma vida pessoal com os acontecimentos mais gerais."

A ampliação do interesse historiográfico por acervos pessoais, em mais especificamente cadernos escolares, tem se tornado crescente. Sua implantação representa uma mudança significativa na história, especialmente como dispositivo pedagógico para estudar sua relação com a cultura e o cotidiano escolar.

Pesquisas desta natureza ainda contribuem para compreender os regimes de historicidade, pois evocam passado, presente e futuro, como enfatizam Souza e Duarte (2016). Da mesma forma, endossam a discussão do panorama educacional da atualidade, que, no contexto do mundo globalizado, é permeada pelos fenômenos do imediatismo e do presentismo.

Cabe destacar ainda que o livro apresenta uma qualidade gráfica lisonjeável, com imagens daquela época, do contexto estudado, bem como dos cadernos e demais objetos do acervo investigado.

Cunha e Souza (2015, p. 24) concluem que o acervo de cadernos escolares do professor Konder, aqui utilizado na perspectiva de uma escrita ordinária, se transformou em um rico material para aprofundamento sobre cultura escolar, em especial uma abordagem sobre formas de organizar o tempo escolar que foge às convenções.

A história como narrativa construída que pretende tornar inteligível determinados fenômenos, pois a "[...] a história torna-se história daquilo que os homens chamaram 
verdades e de suas lutas em torno dessas verdades." (VEYNE, 1998, p. 268). Esta obra apresenta uma verdade, talvez aquela que melhor traduza o modo como Victor Márcio Konder se identificava, ou como gostaria que fosse lembrado... um legítimo "revolucionário letrado".

\section{REFERÊNCIAS}

ARTIÈRES, P. Arquivar a própria vida. Estudos Históricos, Rio de Janeiro, v. 11, n. 21, p. 9-34, 1998. Disponível em: <http://bibliotecadigital.fgv.br/ojs/index.php/reh/article/ view/2061/1200>. Acesso em: 25 fev. 2016.

CUNHA, M. T. S.; SOUZA, F. de. F. Viver e escrever. Cadernos e escritas ordinárias de um professor catarinense (séc. XX). Florianópolis: Insular, 2015.

ESCOLANO BENITO, Augustin. Arqueología y rituales de la escuela. In: MOGARRO, M. J. (Org.). Educação e património cultural: escolas, objetos e práticas. Colibri: Lisboa, 2015. p. 45-60.

MIGNOT, A. C. V. (Org.). Papéis guardados. Rio de Janeiro: UERJ, Rede Sirius, 2003.

OLIVEIRA, M. A. M. de.; SOUZA, J. El de. Perspectivas históricas da escola pública no Brasil. In: RÜCKERT, F. Q.; SOUZA, J. E. de. (Org.). A escola pública no Brasil: temas e problemas. Porto Alegre: Evangraf, 2016. p. 7- 18.

SOUZA, J. E. de.; DUARTE, A. dos. R. O ensino no meio rural: Grupo Escolar Madre Benícia - Novo Hamburgo/RS (1940-1969). In: GRAZZIOTIN, L. S. S.; ALMEIDA, D. B. (Org.). Colégios elementares e grupos escolares no rio grande do sul. Memórias e cultura escolar. Século XIX e XX. São Leopoldo: Oikos, 2016.

SOUZA, J. E. de.; FISCHER, B. T. D. Memórias do ensino em Novo Hamburgo: documentos e acervos (1940-2009). NH na Escola, Novo Hamburgo, p. 2-2, out. 2012.

SOUZA, J. E. de.; MARIANO, R. A linha vando pensamentos: sobre educação e outros mais... Porto Alegre: Pradense, 2011.

VEYNE, P. Como de escreve a história: Foucault revoluciona a história. Brasília: Ed. da $\mathrm{UnB}, 1998$.

VIDAL, L. Acervos pessoais e memória coletiva: alguns elementos de reflexão. FCLAs CEDAP, Campinas, v. 3, n. 1, 2007. 


\section{Revista HIIS'TNIDBR (On-lime}

Notas

${ }^{1}$ Professor e pesquisador do Programa de Pós-Graduação em Educação da Universidade de Caxias do Sul UCS. Vice-Líder do Grupo de Pesquisa: História da Educação, Imigração e Memória (GRUPHEIM). E-mail: jesouza1@ucs.br

Submetido em: 26/04/2017

Aprovado em: 29/05/2017

Publicado em: 04/04/2018 